\title{
Serum magnesium aberrations in furosemide (frusemide) treated patients with congestive heart failure: pathophysiological correlates and prognostic evaluation
}

\author{
N Cohen, D Almoznino-Sarafian, R Zaidenstein, I Alon, O Gorelik, M Shteinshnaider, \\ S Chachashvily, Z Averbukh, A Golik, Z Chen-Levy, D Modai
}

Heart 2003;89:411-416

See end of article for authors' affiliations

Correspondence to: $\operatorname{Dr} \mathrm{N}$ Cohen, Department of Internal Medicine " $\mathrm{F}$ ", Assaf Harofeh Medical Centre, Affiliated to Sackler Faculty of Medicine,

Tel-Aviv University, Zerifin 70300, Israel;

internal6@asaf.health.gov.il

Accepted

17 December 2002

\begin{abstract}
Objectives: To determine the prevalence of hypomagnesaemia and hypermagnesaemia, to discern various factors associated with abnormal serum magnesium, and to estimate prognostic significance of serum magnesium aberrations in patients with congestive heart failure.

Design: Observational study.

Setting: Medical department of a university hospital (tertiary referral centre).

Patients: 404 consecutive patients admitted with congestive heart failure as one of the diagnoses and previously treated with furosemide (frusemide) for at least three months.

Main outcome measures: Clinical, biochemical, and electrocardiographic variables were analysed with respect to serum magnesium aberrations. Following discharge, mortality rates, including sudden death, were registered.

Results: Hypomagnesaemia was found in 50 patients $(12.3 \%)$ and $20(4.9 \%)$ were hypermagnesaemic. Female sex $(p<0.04)$, diabetes mellitus $(p<0.006)$, hypocalcaemia $(p=0.03)$, hyponatraemia $(p<0.05)$, malignant disease $(p=0.05)$, and high fever $(p=0.05)$ were statistically associated with hypomagnesaemia. Renal failure, severe congestive heart failure, and high dose furosemide treatment (>80 mg/day) were associated with hypermagnesaemia $(p<0.001, p=0.05$, and $p<0.03$, respectively). Hypermagnesaemic patients were older and weighed less. On follow up (median duration 43 months), $169(41.8 \%)$ died, with 22 (13\%) sudden deaths. Mortality was highest with hypermagnesaemia, lowest with normomagnesaemia, and intermediate with hypomagnesaemia. After adjustment for renal failure, old age, and severity of congestive heart failure, hypomagnesaemia but not hypermagnesaemia emerged as being significantly associated with shorter survival $(p=0.009)$. No statistical association was found between sudden death and magnesium concentrations.

Conclusions: While hypermagnesaemia seems to represent a prognostic marker only, hypomagnesaemia appears to have an adverse pathophysiological effect. The subgroup of patients at risk for hypomagnesaemia requires frequent serum magnesium determinations and magnesium replacement for as long as hypomagnesaemia persists.
\end{abstract}

M agnesium is the second most abundant intracellular cation after potassium. Ninety nine per cent of total body magnesium is located intracellularly, so that less than $1 \%$ is restricted to the serum. Magnesium plays a key role in a variety of enzymatic reactions. Thus more than 300 enzyme systems, including all ATPases, are magnesium dependent. In addition to energy-requiring metabolic processes and anaerobic phosphorylation, magnesium is involved in protein and DNA synthesis as well as in transmembrane transport mechanisms. ${ }^{1-4}$

Hypomagnesaemia and depletion of intracellular Mg stores, especially in cardiac muscle, have been held responsible for a variety of cardiovascular and other functional abnormalities. These may include various arrhythmias, such as atrial fibrillation and torsade de pointes, impairment of cardiac contractility, and vasoconstriction. These abnormalities can assume critical importance in the context of congestive heart failure. ${ }^{13-7}$

Various pathophysiological factors as well as pharmacological agents, mainly furosemide (frusemide), present in the setting of congestive heart failure may enhance magnesium loss and thus produce magnesium deficiency. ${ }^{15-8}$ Under these circumstances hypomagnesaemia represents a substantial intracellular magnesium depletion in most, if not all, cases ${ }^{47}$ On the other hand magnesium concentrations in various tissues, for example erythrocytes, peripheral mononuclear cells, and skeletal or cardiac muscle, are reported to correlate poorly with each other. ${ }^{3479}$ In addition to the technical difficulties involved in intracellular magnesium assessment, these discrepancies exclude its routine use.

The prevalence of magnesium depletion in congestive heart failure has been reported to be $43-55 \%,{ }^{156}{ }^{10}$ while according to four large scale studies published in English language journals, the prevalence of hypomagnesaemia ranges between $19-38 \%$. $^{10-13}$

Unexpected sudden death is prevalent in congestive heart failure, and has been reported in $30-50 \%$ of affected patients. ${ }^{714}$ Electrolyte disorders including hypomagnesaemia may be implicated. ${ }^{467}$ Many hospital inpatients with congestive heart failure are of advanced age and suffer from various comorbid conditions known to be independently associated with hypomagnesaemia.

We undertook this study with a triple purpose: first, to determine the prevalence of hypomagnesaemia and hypermagnesaemia in a non-selected furosemide treated population of hospital inpatients suffering from congestive heart failure; second, to discern factors, either disease or treatment related, that are associated with abnormal serum magnesium concentrations and thus to define patient subgroups at risk; and finally, to investigate the potential effects of aberrations in serum magnesium on mortality, including sudden death. 
Table 1 Characteristics of 404 patients with hypomagnesaemia ( $\leqslant 0.76 \mathrm{mmol} / \mathrm{l})$, normomagnesaemia $(0.77-1.08$ $\mathrm{mmol} / \mathrm{l})$, and hypermagnesaemia ( $\geqslant 1.09 \mathrm{mmol} / \mathrm{l})$

\begin{tabular}{|c|c|c|c|c|}
\hline Data & $\begin{array}{l}\text { Hypomagnesaemic } \\
\text { patients }(\mathrm{n}=50 ; 12.3 \%)\end{array}$ & $\begin{array}{l}\text { Normomagnesaemic } \\
\text { patients }(n=334 ; 82.6 \%)\end{array}$ & $\begin{array}{l}\text { Hypermagnesaemic } \\
\text { patients }(n=20 ; 4.9 \%)\end{array}$ & $\mathrm{p}$ Value \\
\hline Age (years) & $70.8(12.3)$ & $72.6(10.3)$ & $79.6(5.3)$ & $p<0.005^{*}$ \\
\hline Weight (kg) & 74.7 (13.3) & $73.6(14.7)$ & $65.6(10.9)$ & $p<0.05^{* *}$ \\
\hline Left ventricular ejection fraction (\%) & 35.7 (14.05) & $36.6(13.2)$ & 36.5 (14.2) & NS \\
\hline Blood pH & $7.4(0.05)$ & $7.39(0.0)$ & $7.4(0.0)$ & NS \\
\hline Serum bicarbonate (mmol/l) & $26.1(3.5)$ & $25.4(4.1)$ & $24.7(2.2)$ & NS \\
\hline Serum chloride (mmol/l) & $101.8(4.6)$ & $103(5.3)$ & 102 (4.09) & NS \\
\hline Serum phosphorus (mmol/l) & $1.13(0.23)$ & $1.2(0.26)$ & $1.4(0.42)$ & NS \\
\hline Serum potassium $(\mathrm{mmol} / \mathrm{l})$ & $4.1(0.6)$ & $4.2(0.5)$ & $4.1(0.7)$ & NS \\
\hline Dietary magnesium $(\mathrm{mmol} / \mathrm{d}) \dagger$ & $10.5(4.6)$ & $9.45(4.4)$ & $7.6(0.0)$ & NS \\
\hline
\end{tabular}

Values are mean (SD).

${ }^{*} p<0.005$ between hypomagnesaemic and hypermagnesaemic groups and between normomagnesaemic and hypermagnesaemic groups

** $p<0.05$ between normomagnesaemic and hypermagnesaemic groups.

†Dietary assessment was done in 69 random patients.

\section{METHODS}

\section{Study population}

We studied consecutive patients with chronic congestive heart failure, New York Heart Association (NYHA) functional class II-IV, admitted to hospital in two medical departments for a variety of morbid conditions. Congestive heart failure was of various aetiologies and had been present for at least six months before admission. All patients had been on chronic furosemide treatment at a dosage of at least $40 \mathrm{mg} /$ day for more than three months. We excluded patients who eventually succumbed during the index hospital admission, patients with advanced malignant disease, and patients receiving chemotherapy known to affect magnesium metabolism, or receiving magnesium containing preparations.

\section{Data collection}

On admission, blood was drawn for serum magnesium concentration and other biochemical variables including serum bicarbonate, chloride, phosphorus, potassium, sodium, calcium, creatinine, glucose, cholesterol, triglycerides, and blood $\mathrm{pH}$. All determinations were done using conventional methods. Thorough history taking was followed by physical examination, ECG, chest $x$ ray, and assessment of the dietary intake of magnesium, using the food frequency recall technique. ${ }^{15}$ Subsequently patients were divided into three groups based on their serum magnesium concentrations, defined as follows: normal, $0.77-1.08 \mathrm{mmol} / \mathrm{l}$; low, $\leqslant 0.76 \mathrm{mmol} / \mathrm{l} ;$ high, $\geqslant 1.09 \mathrm{mmol} / \mathrm{l}$. Demographic, clinical, biochemical, and ECG variables were analysed statistically to define parameters associated with hypomagnesaemia or hypermagnesaemia.

Mortality was recorded following discharge. Information concerning the circumstances of death was obtained at one year intervals, either from hospital records or from families or outpatient death certificates.

Sudden death was defined as unexpected circulatory collapse in a clinically stable patient. ${ }^{11}{ }^{12}$

The study was approved by the local ethics committee.

\section{Statistical methods}

In the first stage, univariate analysis was applied, using the $\chi^{2}$ test to determine statistical associations between hypomagnesaemia or hypermagnesaemia and qualitative variables. Analysis of variance (ANOVA) was used for quantitative variables. For variables found on univariate analysis to be significantly associated with a given magnesium aberration $(p<0.05)$, a logistic regression analysis was undertaken to identify those variables that were prevalent in patients with hypomagnesaemia or hypermagnesaemia.

Survival rates were plotted using the Kaplan-Meier method. Mantel-Cox and Breslow statistical tests were applied to evaluate the significance of differences between the curves. The Cox linear regression model was used to identify variables that significantly affected mortality. All statistical analyses were done using BMDP statistical software. ${ }^{16}$

\section{RESULTS}

The study group included 404 sequentially admitted patients, of whom 176 were women and 228 men. Their mean age was 74.5 years. Hypomagnesaemia was found in 50 patients $(12.3 \%)$, normomagnesaemia in $334(82.6 \%)$, and hypermagnesaemia in $20(4.9 \%)$.

Table 1 shows the respective prevalence of quantitative variables in patients with hypomagnesaemia, normomagnesaemia, or hypermagnesaemia. Patients with hypermagnesaemia were significantly older than the patients in the other two groups $(p<0.005)$ and they weighed less than the normomagnesaemic patients $(\mathrm{p}<0.05)$.

All the other variables, including left ventricular ejection fraction, blood $\mathrm{pH}$, and serum bicarbonate, chloride, phosphorus, and potassium concentrations, were comparable in the three subgroups of patients, as were values of daily dietary intake of magnesium.

Table 2 illustrates qualitative variables that were significantly more prevalent in patients with hypomagnesaemia than in those with normomagnesaemia. Female sex $(p<0.04)$, high fever $(p=0.05)$, diabetes mellitus $(p<0.006)$, coexistence of malignant diseases $(p=0.05)$, hyponatraemia $(p<0.05)$, and hypocalcaemia $(p=0.03)$ were all more prevalent in patients with hypomagnesaemia. However, no variable was found to be independently associated with hypomagnesaemia on logistic regression analysis. On the other hand (table 3 ), severe congestive heart failure (NYHA class III-IV) $(\mathrm{p}=0.05)$, high dose furosemide treatment $(p<0.03)$, and renal failure $(p<0.001)$ were significantly more prevalent among hypermagnesaemic than normomagnesaemic patients. However, on logistic regression analysis only renal failure emerged as independently associated with hypermagnesaemia.

Table 4 shows the variables that on statistical analysis were not found to be associated with hypomagnesaemia or hypermagnesaemia. These included decreased left ventricular ejection fraction, atrial fibrillation, ventricular premature beats, atrioventricular or bundle branch block, prolonged corrected QT segment, pulmonary oedema on admission, furosemide treatment for more than one year, hypokalaemia, hypertension, coronary heart disease, hyperlipidaemia, anaemia, severe liver disease, chronic gastrointestinal disease, alcoholism, heavy smoking, and chronic obstructive pulmonary disease. In addition, treatment with various drugs was not found to be associated with alterations in serum 
Table 2 Characteristics of hypomagnesaemic versus normomagnesaemic patients with congestive heart failure, grouped according to serum magnesium concentration

\begin{tabular}{|c|c|c|c|c|}
\hline \multirow[b]{2}{*}{ Characteristic } & \multirow[b]{2}{*}{$\begin{array}{l}\text { Number of } \\
\text { patients }\end{array}$} & \multicolumn{2}{|c|}{ Number (\%) of patients with: } & \multirow[b]{2}{*}{$\mathrm{p}$ Value } \\
\hline & & $\begin{array}{l}\text { Hypomagnesaemia } \\
(\leqslant 0.76 \mathrm{mmol} / \mathrm{l})\end{array}$ & $\begin{array}{l}\text { Normomagnesaemia } \\
(0.77-1.08 \mathrm{mmol} / \mathrm{l})\end{array}$ & \\
\hline \multicolumn{5}{|l|}{ Sex } \\
\hline Male & 228 & $21(42.0)$ & $195(58.4)$ & \multirow[t]{2}{*}{$<0.04$} \\
\hline Female & 176 & $29(58.0)$ & $139(41.6)$ & \\
\hline \multicolumn{5}{|c|}{ Temperature $\left({ }^{\circ} \mathrm{C}\right)$} \\
\hline$<37$ & 301 & $31(64.6)$ & $255(78.0)$ & \multirow[t]{3}{*}{0.05} \\
\hline$>38$ & 22 & $6(12.5)$ & $16(4.9)$ & \\
\hline $37-38$ & 71 & $11(22.9)$ & $56(17.1)$ & \\
\hline \multicolumn{5}{|c|}{ Diabetes mellitus } \\
\hline Yes & 176 & $31(64.6)$ & $135(42.5)$ & \multirow[t]{2}{*}{$<0.006$} \\
\hline No & 209 & $17(35.4)$ & $183(57.5)$ & \\
\hline \multicolumn{5}{|c|}{ Malignant diseases } \\
\hline Yes & 32 & $8(16.0)$ & $24(7.2)$ & \multirow[t]{2}{*}{0.05} \\
\hline No & 372 & $42(84.0)$ & $310(92.8)$ & \\
\hline \multicolumn{5}{|c|}{ Serum sodium (mmol/l) } \\
\hline$\leqslant 135$ & 44 & $10(20.0)$ & $32(9.6)$ & \multirow[t]{2}{*}{0.05} \\
\hline$>136$ & 360 & $40(80.0)$ & $302(90.4)$ & \\
\hline \multicolumn{5}{|c|}{ Serum calcium (mmol/l) } \\
\hline$\leqslant 2.0$ & 16 & $5(10.0)$ & $9(2.7)$ & \multirow[t]{2}{*}{0.03} \\
\hline$>2.0-2.6$ & 388 & $45(90.0)$ & $325(97.3)$ & \\
\hline
\end{tabular}

Table 3 Characteristics of hypermagnesaemic versus normomagnesaemic patients with congestive heart failure, grouped according to serum magnesium concentration

\begin{tabular}{|c|c|c|c|c|}
\hline \multirow[b]{2}{*}{ Characteristic } & \multirow[b]{2}{*}{$\begin{array}{l}\text { Number of } \\
\text { patients }\end{array}$} & \multicolumn{2}{|c|}{ Number (\%) of patients with: } & \multirow[b]{2}{*}{$\mathrm{p}$ Value } \\
\hline & & $\begin{array}{l}\text { Hypermagnesaemia } \\
\text { (>1.09 } \mathrm{mmol} / \mathrm{l})\end{array}$ & $\begin{array}{l}\text { Normomagnesaemia } \\
(0.77-1.08 \mathrm{mmol} / \mathrm{l})\end{array}$ & \\
\hline \multicolumn{5}{|l|}{ NYHA class } \\
\hline ॥ & 239 & $7(36.8)$ & $200(60.8)$ & \multirow[t]{2}{*}{0.05} \\
\hline III-IV & 158 & $12(63.2)$ & $129(39.2)$ & \\
\hline \multicolumn{5}{|c|}{ Furosemide dose (mg/day) } \\
\hline$>80$ & 78 & $8(40.0)$ & 61 (18.5) & \multirow[t]{2}{*}{$<0.03$} \\
\hline$\leqslant 80$ & 322 & $12(60.0)$ & 269 (81.5) & \\
\hline \multicolumn{5}{|c|}{$\begin{array}{l}\text { Renal failure (serum creatinine } \\
\quad>132 \mu \mathrm{mol} / \mathrm{l} \text { ) }\end{array}$} \\
\hline Yes & 163 & $18(90.0)$ & $135(41.0)$ & \multirow[t]{2}{*}{$<.001$} \\
\hline No & 235 & 2 (10.0) & 194 (59.0) & \\
\hline
\end{tabular}

magnesium; these included digoxin, antiarrhythmic drugs, angiotensin converting enzyme inhibitors, and other diuretics.

\section{Survival}

The follow up period extended between 4-60 months. The median follow up was 43 months. During the study period 169 patients died $(41.8 \%)$.

Figure 1 illustrates the cumulative survival curves according to serum magnesium concentrations. Hypermagnesaemia was associated with the worst survival rate, normomagnesaemia with the best, while hypomagnesaemia occupied an intermediate position. Differences between the three curves were significant $(\mathrm{p}<0.001)$. However, following adjustment for age, severity of congestive heart failure, and renal failure, only hypomagnesaemia emerged as significantly associated with shortened survival $(p=0.009)$. In addition, significant associations were found between shortened survival and age $(p=0.001)$, renal failure $(p=0.001)$, and severity of congestive heart failure $(\mathrm{p}=0.028)$.

\section{Causes of death}

Twenty two patients died suddenly (13\%). Statistical analysis did not show any significant association between sudden death and serum magnesium concentration.

\section{DISCUSSION}

Various pathophysiological factors activated in congestive heart failure, as well as pharmacological agents used, combine to produce magnesium depletion with or without hypomagnesaemia. ${ }^{15-7}$ Anorexia, nausea, and reduced intestinal absorption curtail the net magnesium intake. Moreover, activation of the neurohormonal and renin-angiotensin systems, mainly through reduction in effective blood volume, leads to stimulation of aldosterone and antidiuretic hormone (ADH) secretion. These in turn, by virtue of renal sodium and fluid retention, produce a rise in extracellular volume, which inhibits tubular magnesium reabsorption and thus exaggerates urinary magnesium loss. ${ }^{15-7}$ Moreover, magnesium efflux from the blood compartment into cells may take place under the influence of acidosis or increased catecholamine production, both of which are prevalent in congestive heart failure. ${ }^{134} 717$

Renal magnesium reabsorption mainly takes place in the loop of Henle. Thus furosemide and other loop diuretics produce substantial magnesium losses. Thiazides and digoxin, by inhibiting magnesium reabsorption at other tubular sites, also generate magnesuria but to a lesser degree. ${ }^{157}$ On the other hand, spironolactone, amiloride, and triamterene have been shown to reduce urinary magnesium loss. ${ }^{18}$

Hypomagnesaemia has been reported in $19-38 \%$ of patients with congestive heart failure. ${ }^{10-13}$ This is considerably higher 


\begin{tabular}{|c|c|c|c|c|c|}
\hline \multirow[b]{2}{*}{ Characteristic } & \multirow[b]{2}{*}{$\begin{array}{l}\text { Number of } \\
\text { patients }\end{array}$} & \multicolumn{3}{|c|}{ Number (\%) of patients with: } & \multirow[b]{2}{*}{$\mathrm{p}$ Value } \\
\hline & & $\begin{array}{l}\text { Hypomagnesaemia } \\
(\leqslant 0.76 \mathrm{mmol} / \mathrm{l})\end{array}$ & $\begin{array}{l}\text { Normomagnesaemia } \\
(0.77-1.08 \mathrm{mmol} / \mathrm{l})\end{array}$ & $\begin{array}{l}\text { Hypermagnesaemia } \\
(\geqslant 1.09 \mathrm{mmol} / \mathrm{l})\end{array}$ & \\
\hline \multicolumn{6}{|c|}{ Left ventricular ejection fraction (\%) } \\
\hline $30-49 \%$ & 70 & $10(37.0)$ & $56(29.9)$ & $4(25.0)$ & \multirow[t]{3}{*}{ NS } \\
\hline$>50$ & 107 & $9(33.3)$ & $90(48.1)$ & $8(50.0)$ & \\
\hline$<29$ & 53 & $8(29.6)$ & $41(21.9)$ & $4(25.0)$ & \\
\hline \multicolumn{6}{|c|}{ Presence of ventricular premature beats } \\
\hline Yes & 61 & $7(14.0)$ & $51(15.3)$ & $3(15.0)$ & \multirow[t]{2}{*}{ NS } \\
\hline No & 343 & $43(86.0)$ & $283(84.7)$ & $17(85.0)$ & \\
\hline \multicolumn{6}{|c|}{ Atrial fibrillation } \\
\hline Yes & 89 & $12(24.0)$ & 71 (21.7) & $6(30.0)$ & \multirow{2}{*}{ NS } \\
\hline No & 308 & $38(76.0)$ & $256(78.3)$ & $14(70.0)$ & \\
\hline \multicolumn{6}{|c|}{ Atrioventricular or bundle branch block } \\
\hline Yes & 173 & $19(38.0)$ & $144(43.2)$ & $10(50.0)$ & \multirow[t]{2}{*}{ NS } \\
\hline No & 230 & $31(62.0)$ & $189(56.8)$ & $10(50.0)$ & \\
\hline \multicolumn{6}{|l|}{ QTc } \\
\hline Normal & 327 & $48(96.0)$ & $257(96.3)$ & $19(95.0)$ & \multirow[t]{2}{*}{ NS } \\
\hline Prolonged & 13 & $2(4.0)$ & $10(3.0)$ & $1(5.0)$ & \\
\hline Pulmonary oed & ma on admis & & & & \\
\hline Yes & 148 & $15(30.0)$ & $123(37.8)$ & $10(50.0)$ & NS \\
\hline No & 247 & 35 (70.0) & $202(62.2)$ & $10(50.0)$ & \\
\hline Duration of furc & semide treatm & & & & \\
\hline$<1$ year & 99 & $11(23.4)$ & $84(26.3)$ & $5(25.0)$ & NS \\
\hline$>1$ year & 284 & $36(76.6)$ & $233(73.0)$ & $15(75.0)$ & \\
\hline Serum potassiu & $\mathrm{n}(\mathrm{mmol} / \mathrm{l})$ & & & & \\
\hline$\leqslant 3.5$ & 51 & $10(20.4)$ & $37(11.1)$ & $4(20.0)$ & NS \\
\hline $3.6-5.8$ & 352 & 39 (79.6) & $297(88.9)$ & $16(80.0)$ & \\
\hline Comorbid cono & itions & & & & \\
\hline Hypertension & & & & & \\
\hline Yes & 117 & $13(26.5)$ & $98(29.7)$ & $6(30.0)$ & NS \\
\hline No & 282 & 36 (73.5) & $232(70.3)$ & $14(70.0)$ & \\
\hline Coronary arter & disease & & & & \\
\hline Yes & 192 & $20(40.0)$ & $162(48.5)$ & $10(50.0)$ & NS \\
\hline No & 212 & $30(60.0)$ & $172(51.5)$ & $10(50.0)$ & \\
\hline Hyperlipidaem & & & & & \\
\hline Yes & 105 & $11(22.0)$ & $89(26.7)$ & $5(25.0)$ & NS \\
\hline No & 298 & 39 (78.0) & 244 (73.3) & $15(75.0)$ & \\
\hline Anaemia $(\mathrm{Hb}$ & $12 \mathrm{~g} / \mathrm{dll})$ & & & & \\
\hline Yes & 164 & 19 (38.0) & $133(40.3)$ & $12(60.0)$ & NS \\
\hline No & 236 & $31(62.0)$ & 197 (59.7) & $8(40.0)$ & \\
\hline Severe liver dis & ase or chron & gastrointestinal disea & & & \\
\hline Yes & 20 & $4(8.0)$ & $15(4.5)$ & $1(5.0)$ & NS \\
\hline No & 384 & $46(92.0)$ & $319(95.5)$ & $19(95.0)$ & \\
\hline Alcoholism & & & & & \\
\hline Yes & 4 & $0(0.0)$ & $4(1.2)$ & $0(0.0)$ & NS \\
\hline No & 400 & $50(100.0)$ & $330(98.8)$ & $20(100.0)$ & \\
\hline Heavy smoking & or COPD & & & & \\
\hline Yes & 102 & $13(26.0)$ & 83 (24.9) & $6(30.0)$ & NS \\
\hline No & 302 & 37 (74.0) & $251(75.1)$ & $14(70.0)$ & \\
\hline Treatment & & & & & \\
\hline Digoxin & & & & & \\
\hline Yes & 111 & 14 (28.0) & $90(26.9)$ & $7(35.0)$ & NS \\
\hline No & 293 & $36(72.0)$ & $244(73.1)$ & $13(65.0)$ & \\
\hline Antiarrhythmic & drugs & & & & \\
\hline Yes & 64 & $8(16.0)$ & $53(15.9)$ & $3(15.0)$ & NS \\
\hline No & 340 & $42(84.0)$ & 281 (84.1) & $17(85.0)$ & \\
\hline ACE inhibitors & & & & & \\
\hline Yes & 216 & $21(42.0)$ & $184(55.1)$ & 11 (55.0) & NS \\
\hline No & 188 & 29 (58.0) & 150 (44.9) & $9(45.0)$ & \\
\hline Thiazides & & & & & \\
\hline Yes & 14 & $2(4)$ & $10(2.9)$ & $2(10)$ & NS \\
\hline No & 390 & $48(96)$ & 324 (97) & $18(90)$ & \\
\hline Spironolactone & & & & & \\
\hline Yes & 13 & $1(2)$ & 11 (3.3) & $1(5)$ & NS \\
\hline No & 391 & $49(98)$ & $323(96.7)$ & $19(95)$ & \\
\hline
\end{tabular}

than the $12.3 \%$ in the present study. However, those reports either mostly involved outpatients with stable congestive heart failure, ${ }^{10-12}$ or failed to document renal function, ${ }^{10}$ or excluded patients with renal failure. ${ }^{13}$

Our present study, involving 404 furosemide treated patients, is the largest inpatient series so far reported. The participants suffered from various comorbidities, including several conditions known to be independently associated with alterations in magnesium homeostasis. The cause of admission was either an exacerbation of congestive heart failure or a variety of superimposed acute conditions. This group therefore represents a realistic model for a population of hospital inpatients with congestive heart failure, known to be running a greater risk of severe arrhythmias and sudden death. We assume that the relative scarcity of hypomagnesaemia in our patients mainly reflected the high prevalence of renal failure $(49 \%$; 163 of the 398 


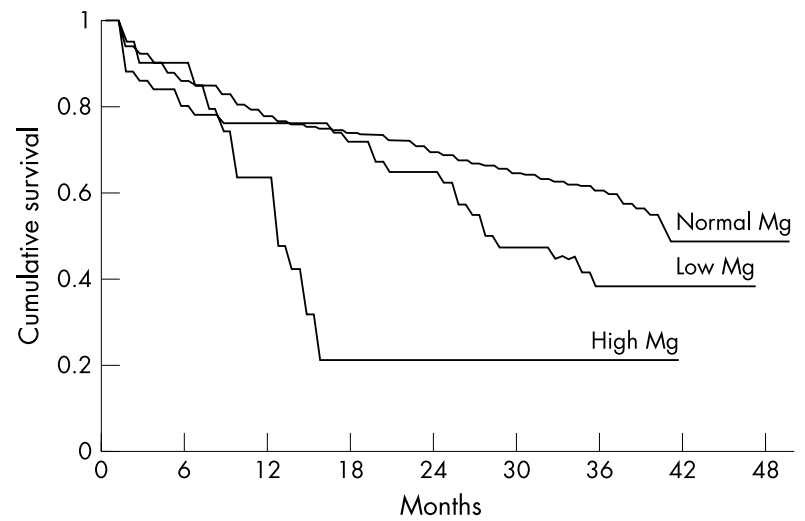

Figure 1 Cumulative survival rates of the three patient groups according to serum magnesium concentrations (low, normal, and high $\mathrm{Mg}$ ).

patients) and the strong association between renal failure and hypermagnesaemia. ${ }^{31112}$ In fact, renal failure emerged as the only independent variable associated with hypermagnesaemia. It is conceivable that in these patients renal failure counterbalanced the haemodynamic, renal, hormonal, and pharmacological factors which may collectively produce hypomagnesaemia. In some of these patients the net result was frank hypermagnesaemia, while in others potential hypomagnesaemia was replaced by normomagnesaemia.

In addition to renal failure, excess use of magnesium containing preparations has been held responsible for

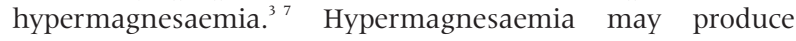
neurological and cardiovascular effects, resulting in mental alterations, neuromuscular dysfunction, hypotension, and various cardiac arrhythmias. These combined effects may be especially dangerous and potentially fatal in the context of congestive heart failure. ${ }^{17}$

Four additional variables were found to be associated with hypermagnesaemia. These were more severe congestive heart failure (functional class III-IV), older age, higher furosemide maintenance dose, and low body weight. We are unaware of any previous documentation of the latter two effects. While all four of these features have a pathophysiological connection with the severity of congestive heart failure, the first three also adversely affect renal function.

The alleged high prevalence of hypomagnesaemia in patients with congestive heart failure on high furosemide doses ${ }^{168}$ has given rise to the suggestion that routine oral magnesium supplementation should be given. ${ }^{6}$ Our results do not support such a practice without prior assessment of renal function.

This is the first study to evaluate the statistical association between hypomagnesaemia and a range of variables in hospital inpatients with congestive heart failure treated with furosemide. Female sex, high fever, diabetes mellitus, malignant diseases, hypocalcaemia, and hyponatraemia were all found to be associated with hypomagnesaemia. While the last four conditions have already been documented, ${ }^{46^{18-21}}$ an association with acute febrile conditions has not been reported before. Stress induced excessive catecholamine secretion and metabolic acidosis, often associated with severe infections, may play a key role. ${ }^{147}$ In this respect it should be noted that rapid shifts in serum magnesium, albeit transient, may produce potentially arrhythmogenic electrophysiological aberrations. ${ }^{22}$

We have been unable to find any reports of an association between female sex and hypomagnesaemia. Whether this finding is incidental or represents a previously unreported physiological observation requires further study. However, it may be relevant that Makkar and colleagues found torsade de pointes to be more common in female than in male patients receiving cardiovascular drugs that prolong cardiac repolarisation. ${ }^{23}$
Hypomagnesaemia and magnesium depletion are known to be arrhythmogenic and may generate potentially fatal rhythm disturbances. ${ }^{15724}$ In most instances hypomagnesaemia represents an advanced stage of intracellular magnesium depletion, ${ }^{45}$ but magnesium depletion may coexist with normomagnesaemia. ${ }^{34}$ Moreover, magnesium depletion is reported to be substantially more prevalent than hypomagnesaemia. ${ }^{1342526}$ It is therefore conceivable that a proportion of our normomagnesaemic patients with congestive heart failure were in fact magnesium depleted.

Various cardiac arrhythmias have been found to be significantly increased in patients with congestive heart failure and hypomagnesaemia. ${ }^{12}{ }^{13} 27$ Such an association was not found in the present study. It should be mentioned, however, that while those investigators did 24 hour ECG recordings, we only used regular ECG tracings taken on admission. Similarly, we found no association between hypomagnesaemia and prolongation of the QT interval, duration of furosemide treatment, hypertension, coronary heart disease, hyperlipidaemia, chronic gastrointestinal diseases, alcoholism, heavy smoking, chronic obstructive airways disease, or the use of other diuretics, ACE inhibitors, or digoxin. ${ }^{1347}$

The prognostic significance of alterations in serum magnesium in patients with congestive heart failure has been investigated in two studies and the findings were conflicting. Eichhorn and colleagues reported that only hypermagnesaemia was associated with a shorter survival. ${ }^{11}$ However, when adjustment for old age and renal impairment was introduced, this correlation was no longer apparent. In contrast, Gottlieb and associates found that the cumulative one year mortality of patients with congestive heart failure was the highest with hypermagnesaemia, lowest with normomagnesaemia, and intermediate with hypomagnesaemia. ${ }^{12}$ On the other hand, significant arrhythmias and sudden death were most prevalent in patients with hypomagnesaemia, while in patients with hypermagnesaemia the incidence of those events was even lower than in the normomagnesaemic group.

In keeping with the data of Gottlieb and associates, ${ }^{12}$ we established the serious prognostic significance of hypomagnesaemia in the present report. Moreover, by further refining the statistical analysis, hypomagnesaemia emerged as a significant factor affecting the prognosis irrespective of the three "classical" comorbid conditions (advanced age, renal failure, and the severity of the heart failure). However, in contrast to Gottlieb's results, the increased mortality in our hypomagnesaemic patients did not involve an excess of sudden deaths. Thus these results tend to emphasise the inhibitory role of magnesium deficiency on cardiac performance through its effects on cardiac contractility, peripheral resistance, and catecholamine release. ${ }^{145}$ The recently demonstrated beneficial effect of spironolactone treatment on the course and survival of patients with congestive heart failure may be relevant in this respect. ${ }^{28} 29$ It is an intriguing possibility that spironolactone might exert this effect, at least in part, through blunting the aldosterone mediated exaggeration of magnesuria.

\section{Conclusions}

In furosemide treated patients with congestive heart failure, hypermagnesaemia is associated with the worst prognosis, normomagnesaemia with the best, and hypomagnesaemia occupies an intermediate position. Hypermagnesaemia does not seem to be the direct underlying cause of the increased mortality, but rather a marker of comorbid conditions affecting the prognosis. Hypomagnesaemia, on the other hand, appears to have a direct prognostic role, mainly but not entirely by compromising cardiac performance. The subgroup of patients with congestive heart failure who are at risk of hypomagnesaemia requires frequent serum magnesium determinations and the provision of magnesium supplementation once hypomagnesaemia is detected. 


\section{ACKNOWLEDGEMENTS}

We express our thanks to Mrs P Lilos of the statistical laboratory, Department of Mathematics, Tel-Aviv University, for the statistical evaluation, and to Mrs R Bidlovski for editorial assistance and the preparation of the manuscript.

\section{Authors' affiliations}

N Cohen, D Almoznino-Sarafian, I Alon, O Gorelik, M Shteinshnaider, S Chachashvily, Department of Internal Medicine " $F$ ", Assaf Harofeh Medical Centre, Tel-Aviv University, Zerifin, Israel A Golik, R Zaidenstein, Department of Internal Medicine "A", Assaf Harofeh Medical Centre

D Modai, Z Averbukh, Department of Nephrology, Assaf Harofeh Medical Centre

Z Chen-Levy, Department of Clinical Chemistry, Assaf Harofeh Medical Centre

\section{REFERENCES}

1 Wester PO. Electrolyte balance in heart failure and the role for magnesium ions. Am J Cardiol 1992:70:44-49C.

2 Al-Ghamdi SMG, Cameron EC, Sutton RAL. Magnesium deficiency pathophysiologic and clinical overview. Am J Kidney Dis 1994;24:737-52.

3 Reinhart RA. Magnesium metabolism: a review with special reference to the relationship between intracellular content and serum levels. Arch Intern Med 1988;148:2415-20.

4 Whang R, Hampton EM, Whang DD. Magnesium homeostasis and clinical disorders of magnesium deficiency. Ann Pharmacother 1994;28:220-6.

5 Gottlieb SS. Importance of magnesium in congestive heart failure. Am J Cardiol 1989:63:39-42G.

6 Leier CV, Dei Cas L, Metra M. Clinical relevance and management of the major electrolyte abnormalities in congestive heart failure: hyponatremia, hypokalemia, and hypomagnesemia. Am Heart 1994; 128:564-74

7 Douban S, Brodsky MA, Whang DD, et al. Significance of magnesium in congestive heart failure. Am Heart J 1996;132:664-71.

8 Davies DL, Fraser R. Do diuretics cause magnesium deficiency? Br J Clin Pharmacol 1993;36:1-10.

9 Ralston MA, Murnane MR, Kelley RE, et al. Magnesium content of serum, circulating mononuclear cells, skeletal muscle, and myocardium in congestive heart failure. Circulation 1989:80:573-80.

10 Dyckner T, Wester PO. Plasma and skeletal muscle electrolytes in patients on long-term diuretic therapy for arterial hypertension and/o congestive heart failure. Acta Med Scand 1987;222:231-6.

11 Eichhorn EJ, Tandon PK, DiBianco R, et al. Clinical and prognostic significance of serum magnesium concentration in patients with severe chronic congestive heart failure: the PROMISE study. J Am Coll Cardiol 1993;21:634-40.
12 Gottlieb SS, Baruch L, Kukin ML, et al. Prognostic importance of the serum magnesium concentration in patients with congestive heart failure. J Am Coll Cardiol 1990;16:827-31.

13 Ceremuzynski L, Gebalska J, Wolk R, et al. Hypomagnesemia in heart failure with ventricular arrhythmias. Beneficial effects of magnesium supplementation. J Intern Med 2000;247:78-86.

14 Teerlink JR, Massie BM. The role of beta-blockers in preventing sudden death in heart failure. J Card Fail 2000;6(2 suppl 1):25-33

15 Block G, Subar AF. Estimates of nutrient intake from a food frequency questionnaire. J Am Diet Assoc 1992;92:969-77.

16 Dixon WJ, ed. BMDP statistical software. Los Angeles: University of California Press, 1992

17 Kiaer A, Hesse B. Heart failure and neuroendocrine activation: diagnostic, prognostic and therapeutic perspectives. Clin Physiol 2001;21:661-72.

18 Whang R, Oei TO, Aikawa JK, et al. Predictors of clinical hypomagnesemia. Hypokalemia, hypophosphatemia, hyponatremia, and hypocalcemia. Arch Intern Med 1984;144:1794-6.

19 Lum G. Hypomagnesemia in acute and chronic care patient populations. Am J Clin Pathol 1992;97:827-30.

20 D'Erasmo E, Celi FS, Acca M, et al. Hypocalcemia and hypomagnesemia in cancer patients. Biomed Pharmacother 1991;45:315-17.

21 Tosiello L. Hypomagnesemia and diabetes mellitus. A review of clinical implications. Arch Intern Med 1996;156:1143-8.

22 DiCarlo LA, Morady F, de Buitleir M, et al. Effects of magnesium sulfate on cardiac conduction and refractoriness in humans. J Am Coll Cardiol 1986; 7: 1356-6.

23 Makkar RR, Fromm BS, Steinman RT, et al. Female gender as a risk factor for torsades de pointes associated with cardiovascular drugs. JAMA 1993;270:2590-7

24 Gettes LS. Electrolyte abnormalities underlying lethal and ventricular arrhythmias. Circulation 1992;85(suppl I):-170-6.

25 Cohen N, Alon I, Almoznino-Sarafian D, et al. Metabolic and clinica effects of oral magnesium supplementation in furosemide-treated patients with severe congestive heart failure. Clin Cardiol 2000;23:433-6.

26 Dorup I, Skajaa K, Clausen T, et al. Reduced concentrations of potassium, magnesium, and sodium-potassium pumps in human skeletal muscle during treatment with diuretics. BM 1988;296:455-8.

27 Bashir Y, Sneddon JF, Staunton HA, et al. Effects of long-term ora magnesium chloride replacement in congestive heart failure secondary to coronary artery disease. Am J Cardiol 1993;72:1156-62.

28 Pitt B, Zannad F, Remme WJ, et al. The effect of spironolactone on morbidity and mortality in patients with severe heart failure. Randomized aldactone evaluation study investigators. N Engl J Med 1999;341:709-17.

29 Soberman JE, Weber KT. Spironolactone in congestive heart failure. Curr Hypertens Rep 2000;2:451-6.

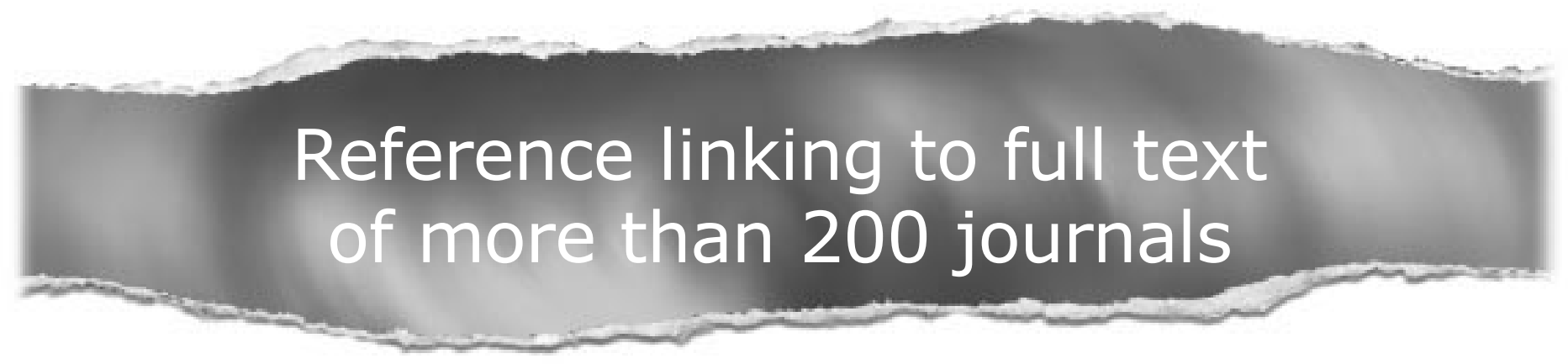

\section{Toll free links}

You can access the FULL TEXT of articles cited in Heart online if the citation is to one of the more than 200 journals hosted by HighWire (http://highwire.stanford.edu) without a subscription to that journal.

There are also direct links from references to the Medline abstract for other titles.

\section{www.heartjnl.com}

